\title{
Correspondence
}

Letters to the Editor should not exceed 500 words.

Cerebral Thrombosis and Oral Contraceptives

W. Bryan Jennett, F.R.C.S. ................173

Hazards from Raw Fish

K. Patricia Carpenter, M.B., and R. G. A.

Sutton .....................................173

Publicity for New Drugs

I. W. B. Grant, F.R.C.P.ED. .............174

Amoebic Colitis Exacerbated by Steroids

C. S. Goodwin, M.D. .......................174

Beta-Adrenergic Stimulants in Asthma

M. C. S. Kennedy, M.R.C.S. ..............174

Type III Hyperlipoproteinaemia

B. M. Rifkind, M.R.C.P.ED.

Rhesus Isoimmunization and Therapeutic

Abortion
P. L. C. Diggory, F.R.c.s.

.174

P. L. C.

$\ldots .175$

Survival after 204 Defibrillations

D. S. P. Dickson, M.R.A.C.P., and P. I.

Parkinson, M.B. .................

T. S. Matthews, M.R.C.P.
Creatinine Content of Uripe and Bacterial

Growth
W. R. Cattell, M.D., and others ...........175

Manson and Malaria

H. G. Calwell, M.D.

Paraneoplastic Hypercalcaemia and Renal Malignancy

M. A. Sperber, M.D. .......................176

Vitamin $C$ and the Elderly

J. Andrews, M.D., and M. Brook, PH.D. ...176

How Many Authors Can Collaborate ?

J. W. Dickson, F.R.C.s.

Disodium Cromoglycate in Exercise-induced Asthma

R. S. McNeill, F.R.C.P.ED., and others ;

J. S. G. Cox, PH.D. .....................176

Dangers of Certain Appetite Suppressants

. F. J. Prime, M.D. ............................

Patients

E. G. McQueen, F.R.A.c.P.
Intermittent Methohexitone

P. A. Foreman, B.D.S

Degenerative Tropical Neur

B. O. Osuntokun, M.R.C.P., and G. L.

Monekosso, F.R.C.P. .....................178

Pain in the Neck

A. Stoddard, M.B.

Aormonal Management of Breast Cancer

F. M. Muggia, M.D. .....................179

Cardiomyopath

R. G. Twycross, B.M.

D. A. Smith, M.R.C.P.ED., F.F.R. ..........180

Ultrasonics in Medicine

D. Gordon, D.M.R.D. ..................... 180

Pampered Patients

S. L. H. Smith, D.T.M.\&H.

Clearer References

J. M. Goldman, M.R.C.P.

M. K. Tandon, M.D., and G. Freed, M.B. 180 Armed Forces Pay Rise

Army General Practitioner ................180

\section{Cerebral Thrombosis and Oral Contraceptives}

SIR,-Dr. M. P. Vessey and Professor Richard Doll (14 June, p. 651) find that oral contraceptives increase sixfold the risk of cerebral thrombosis in women aged 16-40 who have no known predisposing cause. It is good that despite the small numbers they have now been able to reach a definite conclusion, based on such a careful statistical inquiry. But some of the supporting evidence quoted comes from less well-controlled studies which call for scrutiny. Bergeron and Wood ${ }^{1}$ reported an increase in angiographically verified vascular occlusions in 1966 as compared with 1960, not in hospital admissions for cerebral thrombosis; their 55 and 58 patients with " non-occlusive disease" included those with aneurysms, tumours, haematomas, etc. Three features of this report are surprising: the similar number of cases investigated in these two years during which most hospitals greatly increased their turnover, the fact that only one patient was pregnant, and the fact that no case had internal carotid occlusion.

In our study of 146 patients aged 15-45 who had carotid angiograms and who were diagnosed on discharge as suffering from carotid territory ischaemia, the proportion of non-pregnant women was similar in recent as in former years. ${ }^{2}$ The number of annual referrals more than doubled during this period (1956-65), but this was exactly balanced by more men in the same age group. Of the 42 non-pregnant women, 40 never had oral contraceptives. More than a third of the women in this age group with ischaemic strokes were pregnant or puerperal, and the mortality rate was three times as great as in the non-pregnant women. Our experience accords with that of Dr. Vessey and Professor Doll in that cerebral ischaemia was usually due to arterial rather than venous occlusion, and this applied equally to the pregnant and puerperal patients, although the distribution of lesions was different. The middle cerebral artery was more often affected in the pregnant group and the internal carotid in the neck in the non-pregnant group. ${ }^{3}$ It is to be hoped that eventually statisticians will compare the risk of pregnancy with the risk of contraception in relation to this particular complication, both as regards incidence and mortality.

Dr. Vessey and Professor Doll allude to the difficulty of establishing the diagnosis and apologize for the term " cerebral throm bosis." The term cerebral ischaemia would seem preferable as it does not anticipate the pathological mechanism involved. It would seem wise to make clear in all reports whether or not the diagnosis has been based on angiography, because it is becoming increasingly recognized that other intracranial pathology can mimic vascular lesions. In this regard it is not absolutely clear whether the patients with an "uncertain diagnosis" (Table VIII) were those who had a normal angiogram or who did not have an angiogram at all.

The disparity in findings between differen series may rest on definitions such as this and on the criteria used in collecting cases. Thus Dr. Vessey and Professor Doll excluded all patients with a predisposing cause for thromboembolic disease, while Salmon et al., reviewing the literature, found that such factors operated in 52 patients developing strokes in association with oral contraceptives; they were a feature of $26 \%$ of the Glasgow series. This latter series excluded vertebrobasilar disease, which made up $26 \%$ of Salmon's series.-I am, etc., \section{Department of Neurosurgery,
Killearn Hospital,}

W. Bryan Jennett Glasgow.

\section{REFERENCES}

Bergeron, R. T., and Wood, E. H., Radiology,
1969, 92, 231. Jennett, W. B., and Cross, J. N., Lancet, 1967, 1, 1019

Cross, J. N., Castro, P. O.. and Jennett, W. B. Salmon, M. L., Winkelman, J. Z. and Gay,
A. J., fournal of the American Medical Associa-
tion, $1968,206,85$.

\section{Hazards from Raw Fish}

SIR,-In the answer to the question on the health hazards from eating raw fish (28 June, p. 812), risks due to bacteria have not been mentioned. Two important diseases of bacterial origin are botulism and the so-called Japanese fish-poisoning.

Outbreaks of botulism, especially those due to Clostridium botulinum type $\mathrm{E}$, have been associated with the consumption of unheated or partially heated fish or fish products which have been smoked, dried, salted, or fermented. Outbreaks have been reported from several countries where such products form an important part of the normal diet, and certainly occur in Japan. ${ }^{1}$ Raw or preserved fish of either marine or fresh water origin may be involved, and home processed fish or fish products are a special risk. ${ }^{2}$

Botulism is an intoxication and not an infection. $\mathrm{Cl}$. botulinum type E can multiply and form lethal toxin in fish at low temperatures $\left(4-5^{\circ}\right.$ C.), and the practice of prolonging the shelf life by storing raw fish in vacuum-packed plastic bags at temperature between $5-10^{\circ} \mathrm{C}$. may be potentially dangerous.

Japanese fish-poisoning is an acute gastroenteritis arising from the consumption of raw sea fish or fish products, and the causative organism is a halophilic vibrio, now known as Vibrio parahaemolyticus. ${ }^{3}$ This type of food-poisoning is, so far, exclusive to Japan, and occurs mainly in summer. Indeed, $V$. parahaemolyticus is probably the commonest cause of bacterial food-poisoning in Japan at present.

Outside Japan, attempts in Britain and elsewhere to find this organism in outbreaks associated with uncooked shellfish such as oysters have failed. However, other halophilic marine vibrios have been incriminated in gastroenteritis syndromes in certain parts of the world.

Cholera may be another hazard from eating semi-raw shell-food preparations such as "alamang," a food paste made from fresh- 
water shrimps, and this certainly seems to have played a role in the 1961 outbreak of cholera in the Philippines. ${ }^{5}$ Travellers to countries where raw fish and other fish products are commonly consumed should be made well aware of the potential risks. We are, etc.,

\section{K. Patricia Carpenter. Ross G. A. Sutton. \\ Central Public Health Laboratory.}

RBFBRENCES

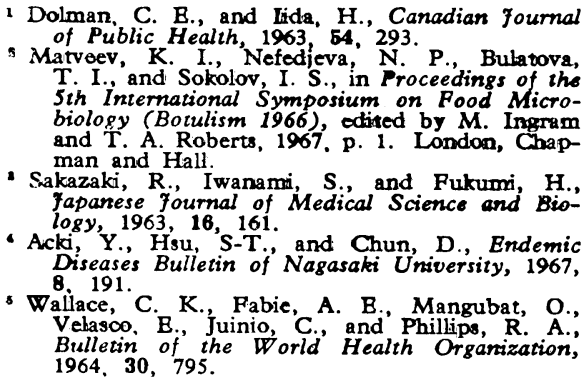

\section{Publicity for New Drugs}

SIR,-During recent years there has been an important change in the methods used by pharmaceutical firms to bring their products to the attention of hospital physicians. Approaches by persuasive representatives armed with free samples have become less frequent, and their place is being taken by exhibitions, film shows, and scientific symposia, designed to secure maximum publicity for some particular drug. During the past few months there has been a disturbing new development in this method of sales promotion. The proceedings of a scientific symposium on the effects of a new drug are widely circulated to the medical profession by the manufacturers who sponsor it, and the publication is illustrated by photographs of the contributors, side by side with strident advertisements for the drug itself. This must be extremely embarrassing for the contributors to the symposium, and one wonders whether their consent has been obtained for the reproduction of their photographs in this context.

Scientific symposia promoted by pharmaceutical companies have made many valuable contributions to medical knowledge, and it would be unfortunate if they were brought into disrepute by the irresponsible actions of a small minority of unscrupulous firms. I am, etc.,

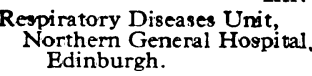

\section{Amoebic Colitis Exacerbated by Steroids}

SIR,-The observation by Drs. S. R. Kanani and R. Knight (7 June, p. 613) that corticosteroids may precipitate an exacerbation of amoebic colitis is supported by observations in this hospital in Addis Ababa.

Among our Ethiopian patients with leprosy there are many with acute neuritis, those with paucibacillary leprosy being treated with corticosteroids. It is my experience that, when patients who are being treated with corticosteroids complain of abdominal pain, frequently trophozoites of Entamoeba histolytica are found in the stool, which were not found on admission to hospital. These exacerbations of amoebic colitis respond readily to standard anti-amoebic therapy, and are not an indication for cessation of steroid therapy.-I am, etc,

$$
\begin{aligned}
& \text { All-Africa Leprosy and Rehabilitation } \\
& \text { Training Centre. } \\
& \text { Princess Zenebework Hospital, } \\
& \text { Addis Ababa, Bthiopia. }
\end{aligned}
$$

\section{Beta-Adrenergic Stimulants in Asthma}

SIR,-I was interested to read the report from Edinburgh by Dr. Y. F. J. Choo-Kang, and others ( 3 May, p. 287), comparing the effect of isoprenaline, orciprenaline, and salbutamol given by inhalation to patients with asthma. A comparison of similar doses of orciprenaline and salbutamol was carried out concurrently in this laboratory; the results, which were published in detail elsewhere, ${ }^{1}$ confirm the Edinburgh findings except that in our hands the difference between the two drugs appeared to be slightly greater. Our time response studies are summarized in the Figure.

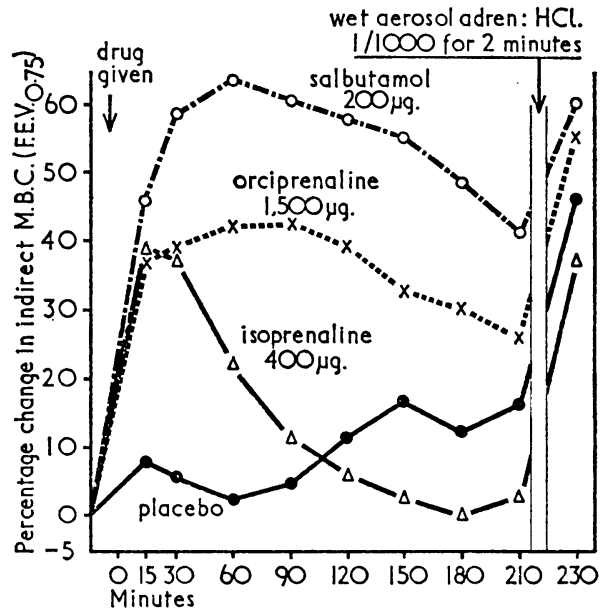

Percentage changes in F.E.V .0.75 after the inhalation of salbutamol, orciprenaline, isoprenaline, and placebo. The orciprenaline and isoprenaline were delivered by commencially available cartridges.

Orciprenaline, because of its longer action ${ }^{2}$ and lower incidence of cardiovascular effects, has hitherto been preferred to isoprenaline in this clinic when an adrenergic aerosol is required. Since the above study suggested that salbutamol might represent yet a further improvement, this compound was investigated in other ways to assess its value in clinical use. I would like briefly to record the findings.

Thirty-seven patients were given pressurepacked salbutamol inhalers (100 $\mu \mathrm{g}$. per puff) to use as an alternative to orciprenaline sulphate (750 $\mu \mathrm{g}$. per puff) for routine self-administration. At the end of a month 25 stated that they preferred salbutamol to any adrenergic aerosol they had tried previously, five preferred orciprenaline, and seven had no preference. The distribution of preferences was thus very similar to that reported from Edinburgh.

Patients attending the clinic are routinely given a two-minute inhalation of a wet adrenaline tartrate aerosol ( 1 in 1,000 solution) from a Collison inhaler as a test for the degree of reversible airway obstruction at their weeldy attendance. The forced expiratory volume is measured before, and five minutes after, this inhalation. For one month all patients received two puffs from a pressure-packed salbutamol aerosol $(200 \mu \mathrm{g}$.) instead of adrenaline. A total of 241 patients were thus treated with salbutamol aerosol on at least four occasions. When the response was compared with that recorded after wet adrenaline during the months preceding and following, it was found that 169 patients responded equally to both agents, 21 responded better to the $200 \mu \mathrm{g}$. of salbutamol, and 51 to the two-minute inhalation of adrenaline.

These results indicate that salbutamol is indeed a very effective bronchodilator, since experience suggests that our two-minute inhalation of wet adrenaline aerosol produces something approaching the maximum improvement that can be achieved by adrenergic drugs in the individual patient on any given day.-I am, etc.,

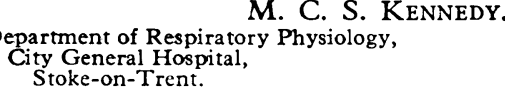

S KENNEDY.

City General Hospital,
Stoke-on-Trent.

REFERENCES

Kennedy, M. C. S., and Simpson, W. T., British fournal of Diseases of the Chest, 1969, 63, 165. posium on Bronchitis, edited by posium on Bronchitis, edited by N. G. M. Royal Van Gorcum, 1964.

\section{Type III Hyperlipoproteinaemia}

SIR,-I have read Dr. P. Borrie's paper on type III hyperlipoproteinaemia (14 June, p. 665) with interest. While on the basis of the plasma lipid levels, the clinical features, and the response to treatment it is probable that most, if not all, of his patients do have this disorder, it should be emphasized that its certain diagnosis depends on the demonstration of beta-lipoprotein of abnormally low density by a combination of preparative ultracentrifugation and lipoprotein-paper electrophoresis. $^{1}$ Failure to do this may lead to type III being confused with other hyperlipoproteinaemias. The difficulties which Dr. Borrie alludes to in assigning cases to the various lipoprotein types may be resolved by strict adherence to the criteria laid down by Fredrickson et al. ${ }^{1}$

Dr. Borrie's description of the findings on electrophoresis in polyacrylamide gel might give the impression that the disease is characterized by a "greatly increased, very low density lipoprotein (pre-beta-lipoprotein) band"; when paper electrophoresis is employed $^{1}$ the plasma of type III hyperlipoproteinaemia usually exhibits the so-called "broad" beta band, and any pre-beta band due to normal very low density lipoprotein is incidental.

The genetics of the disorder are also worthy of mention. On the basis of their studies on 52 patients from 38 kindred, Levy and Fredrickson ${ }^{2}$ suggest that it results from the inheritance of a pair of autosomal recessive genes. The two families described by Dr. Borrie, in whom pairs of siblings were found to be affected, are compatible with this view.-I am, etc.,

B. RIFRIND.

Royal Infirmary

\section{REFERENCES} 1 Fredrickson. D. S., Levy, R. I., and Lees, R. S., Levy, R. I., and Fredrickson, D. S., American 